Research, part of a Special Feature on Effects of Roads and Traffic on Wildlife Populations and Landscape Function

\title{
Quantifying the Road-Effect Zone: Threshold Effects of a Motorway on Anuran Populations in Ontario, Canada
}

\author{
$\underline{\text { Felix Eigenbrod }}^{1}, \underline{\text { Stephen J. Hecnar }}^{2}$, and Lenore Fahrig $^{3}$
}

\begin{abstract}
The negative effect of roads on wildlife is recognized as a major contributor to the global biodiversity crisis, with anurans being among the most vulnerable groups overall. The "road-effect zone," i.e., the extent of significant ecological effects from the edge of a road (Forman and Alexander 1998), has important management implications, but has never been quantified for anurans. In the first study of its kind, we measured the extent and type of relationship underlying the road-effect zones of a motorway with a high proportion of heavy-truck traffic, particularly at night (Highway 401) for anuran species richness and relative abundance. We surveyed 34 ponds located 68-3262 m from the edge of the motorway, and used piecewise and linear regressions to determine if road-effect zones were clearly delineated by ecological thresholds. We found road-effect zones of 250-1000 $\mathrm{m}$ delineated by ecological thresholds for four of seven species and species richness, and road-effect zones of well beyond $1000 \mathrm{~m}$ best described by linear regressions for two species. The negative effect of Highway 401 was unexpectedly strong for four of seven species suggest that, in addition to road mortality, very high nighttime truck traffic can actually lead to reduced use of breeding habitat near the motorway either by acting as a barrier to forest habitat on the other side of the highway and/or because of traffic noise. Our results show that most anurans are likely to have reduced abundances near motorways, but that both the extent of the effect of this type of road and the underlying relationship vary considerably between species. Furthermore, the noise and/or barrier effect of very high nighttime traffic volumes can lead to negative effects of motorways even on species that are relatively unaffected by direct road mortality.
\end{abstract}

Key Words: accessible habitat; amphibian decline; anuran populations; ecological thresholds; forests; fragmentation; habitat loss; piecewise regression; road ecology.

\section{INTRODUCTION}

The negative effect of roads on wildlife is recognized as a major contributor to the global biodiversity crisis for many taxa (Forman and Alexander 1998, Trombulak and Frissell 2000, Coffin 2007). The three main effects that roads have on wildlife are to cause direct mortality through traffic; to act as a movement barrier leading to population subdivision and resource inaccessibility; and to reduce populations through habitat loss (Jaeger et al. 2005). Behavioral responses to roads and traffic will influence which of these three effects has the greatest impact on a species. High avoidance of the road surface and/or traffic will increase the barrier effect of a road, but decrease direct mortality, whereas avoidance of road noise will increase the habitat loss effect of the road (Jaeger et al. 2005). There is also increasing evidence that traffic noise can lead to auditory interference, affecting breeding behavior and reproductive success (Warren et al. 2006), and pollution from roads, e.g., from road salt, can also affect some species (Forman and Alexander 1998, Sanzo and Hecnar 2006). Although species as diverse as ground beetles (Keller and Largiader 2003) and grizzly bears (Mace et al. 1996) are known to be negatively affected by roads, amphibians (reviewed in Cushman 2006) are among the most vulnerable groups overall. This is because this group exhibits low traffic avoidance (Bouchard

\footnotetext{
${ }^{1}$ Geomatics and Landscape Ecology Research Laboratory, Department of Biology, Carleton University, Ottawa, Canada, ${ }^{2}$ Department of Biology, Lakehead University, Thunder Bay, Ontario, Canada, ${ }^{3}$ Geomatics and Landscape Ecology Research Laboratory, Department of Biology, Carleton University, Ottawa, Ontario Canada
} 
et al., unpublished manuscript), relatively slow movement speed (Schlupp and Podloucky 1994), and high vagility (Carr and Fahrig 2001), leading to high road mortality (e.g., Ashley and Robinson 1996). Modeling work by Jaeger and Fahrig (2004) shows that direct mortality generally has a greater negative effect on wildlife populations than barrier effects caused by road or traffic avoidance.

An important question for management and mitigation of road effects on wildlife is how far from the road do its effects extend, i.e., the "road-effect zone" (Forman and Alexander 1998). Thus far, only four studies have quantified the extent of road-effect zones. Reijnen et al. (1995) found road-effect zones (significant reductions in population density) for Dutch birds varied from 40-2800 $\mathrm{m}$ in width, depending both on the species and traffic volumes on the roads. Forman and Deblinger (2000) mapped the road-effect zone of a major highway in Massachusetts for wildlife, based on field surveys and local sightings (birds, invasive plants, moose, deer), and estimates based on adjacent land cover information and the existing literature for amphibians. They estimated the width of the roadeffect zone to be approximately 100-1000 m. Boarman and Sazaki (2006) showed that secondary highways result in a road-effect zone of at least 400 $m$ for desert turtles in the USA, whereas Semlitsch et al. (2007) showed that minor forestry roads in the eastern USA resulted in a road-effect zone of $35 \mathrm{~m}$ for salamanders. To date, no study has quantified road-effect zones for anurans, despite the welldocumented vulnerability of this group to hightraffic roads (Fahrig et al. 1995, Vos and Chardon 1998, Carr and Fahrig 2001, Eigenbrod et al. 2008a).

In addition to knowing its extent, it is also important for conservation biologists to know what type of relationship determines the road-effect zone. A road-effect zone can be delineated by an ecological threshold, i.e., a point or zone at which a relatively rapid change occurs from one ecological condition to another (Huggett 2005, Luck 2005, Groffman et al. 2006). A road-effect zone is delineated by an ecological threshold if there is an abrupt transition from an effect of the road on a species to no effect (Fig. 1). The statistical significance of this transition (or "difference-in-slope" parameter) can be tested using a piecewise regression (Muggeo 2003, Toms and Lesperence 2003). The main advantage for managers and policy makers of a road-effect zone delineated by an ecological threshold is that the affected area will be clearly defined. In this case, decision makers do not need to consider the effects of the road beyond the threshold distance, and also have strong evidence for management actions to reduce the impact of the road up to the threshold distance. A road-effect may also be revealed by a gradual increase in the abundance of some species with increasing distance from a road to the point beyond which no effect can be detected (Fig. 1). In this case, a road-effect zone cannot be clearly delineated as there is no threshold, making management recommendations more difficult.

Our purpose was to quantify the extent of the roadeffect zone of a motorway on anuran species richness and relative abundance. We compared piecewise and linear regressions to determine if clear road-effect zones delineated by ecological thresholds exist, and if so, at what distance from the motorway they occur. A secondary goal was to determine the magnitude of the effect of the motorway on the anurans in the study area. Ours is the first study to investigate the type of relationships that characterize road-effect zones, and the first to quantify road-effect zones for anurans. We expected that the main negative effect of the motorway on anurans would be direct mortality for reasons discussed earlier, but also that the barrier effect of this road to be high as we would expect the probability of an anuran successfully crossing the motorway would be very low (Hels and Buchwald 2001).

\section{METHODS}

\section{Study design}

We selected 34 ponds located between 68 and 3262 $\mathrm{m}$ away from Highway 401 along a $58 \mathrm{~km}$ rural section of the highway in eastern Ontario, Canada (Fig. 2). Based on earlier work (Eigenbrod et al. $2008 a, b)$, we predicted a priori that the road-effect zone would be most severe within $500 \mathrm{~m}$ of the edge of Highway 401. To maximize our statistical power to detect this effect, we sampled all available ponds in the study area that were within $500 \mathrm{~m}$ of the edge of the highway within the study area (17 in total), and then selected an additional 17 ponds located 500-3262 $\mathrm{m}$ away from the highway to quantify road effects beyond this distance. We sampled all ponds in 2006, and resampled a 22 pond subset of these in 2007, which was representative of the distribution of all 34 ponds. We only resampled a 
Fig. 1. An example of two types of road effect zones: one sharply defined by a threshold and the other characterized by a gradual, approximately linear increase in population size with increasing distance from the road until some distance beyond which no effect can be detected.

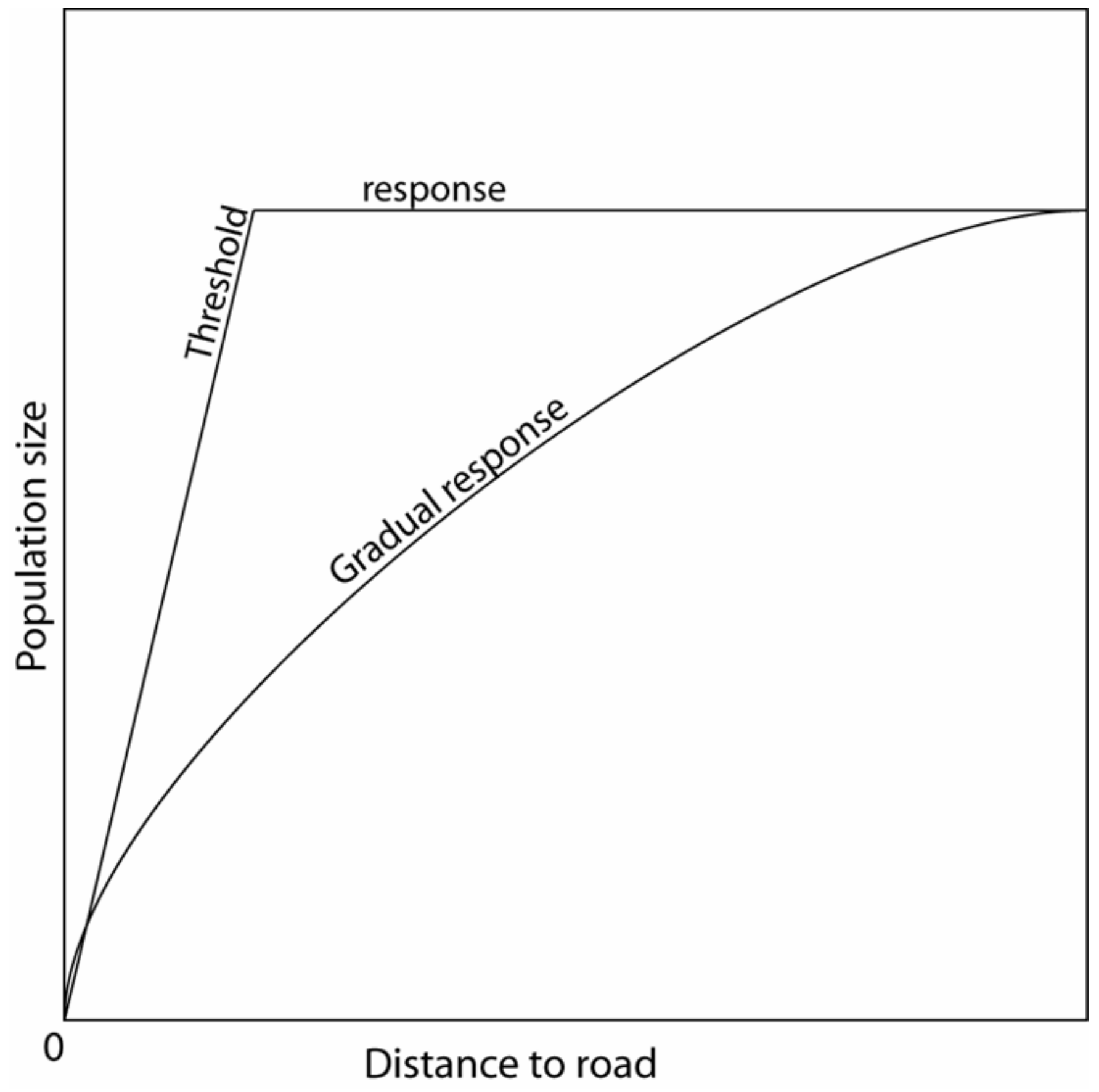


subset because of logistic constraints. Ponds were located at least $500 \mathrm{~m}$ apart to ensure that each pond was a distinct population (Petranka et al. 2004). Highway 401 is the main route connecting Toronto and Montreal, the two largest cities in Canada. In the study area, it is a four-lane motorway with an average traffic volume of 18,300 vehicles/d in September 2006 (Mary Anne Griepsma, Ontario Ministry of Transportation, personal communication). All other roads in the study area (Fig. 2) had low traffic volumes $(<1000$ vehicles/d on all but 1 road, which had 3000 vehicles/d). Our earlier work (Eigenbrod et al. 2008a) showed that these low traffic volumes had little effect on anuran populations, especially relative to the effect of the traffic on Highway 401.

\section{Anuran field surveys}

We conducted eight auditory night chorus surveys and four visual day surveys to assess the species richness and relative abundances of anurans at or near the sampling ponds in 2006. Nine of the 14 anuran species found in the Great Lakes Basin (Harding 1997) are present in the study area: wood frog (Rana sylvatica LeConte), spring peeper (Pseudacris crucifer Wied-Neuwied), western chorus frog (Pseudacris triseriata Wied-Neuwied), northern leopard frog (Rana pipiens Schreber), American toad (Bufo americanus Holbrook), gray treefrog (Hyla versicolor LeConte), green frog (Rana clamitans Latreille), mink frog (Rana septentrionalis Baird), and bullfrog (Rana catesbeiana Shaw).

Chorus surveys in 2006 were conducted between 1 April and 12 July, and were timed so that there were at least two surveys during the peak breeding season of each species present in the region. Chorus surveys followed a modified version of the Marsh Monitoring Protocol (Bishop et al. 1997, Eigenbrod et al. 2008a). We began surveys half an hour after sunset and finished before midnight. We surveyed each pond for $5 \mathrm{~min}$, and recorded the number of calling males at or within $100 \mathrm{~m}$ of the pond in one of four abundance classes: 0 (no individuals calling), 1 (individuals can be counted and calls are not overlapping), 2 (calls of $<15$ individuals can be distinguished, some overlap of calls), 3 (calling individuals too numerous to count or $\geq 15$ individuals calling, calls overlapping). We included calling from within $100 \mathrm{~m}$ of the pond to account for the preference of several species (wood frog, spring peeper, gray treefrog) to breed in ephemeral vernal pools (Skelly et al. 1999), which were very common in the forests adjacent to our sampling ponds. The ponds were divided into four routes, and were surveyed over two nights that were as close to consecutive as weather conditions permitted. Surveys were only conducted on warm evenings (average survey temperature 1 April-9 May: 9.3 ${ }^{\circ}$ $\mathrm{C} \pm$ 4.1 SD; 24 May-12 July: $\left.20.3{ }^{\circ} \mathrm{C} \pm 3.7 \mathrm{SD}\right)$ with little wind (average Beaufort wind scale reading $1.04 \pm 1.15 \mathrm{SD})$. The order in which the routes were sampled within a survey was randomized, and the order in which ponds were surveyed within a route was alternated between forwards, backwards, starting at the middle of the route and moving forwards, and starting at the middle and moving backwards to vary the time of the survey for each pond. We also conducted eight call surveys between 2 April and 12 July, 2007 using the same protocol as in 2006.

We conducted visual surveys between 8 May and 8 July, 2006 to correspond with the peak breeding season of aquatic frogs (leopard frog, green frog, mink frog, bullfrog). These species are conspicuous during their breeding seasons in visual surveys, but are easily missed using call surveys alone (de Solla et al. 2005). Each survey was conducted between 0900 and $1700 \mathrm{~h}$ over $4 \mathrm{~d}$. Adults were counted as a surveyor slowly walked along the edge of the pond or through shallow emergent vegetation. Search effort was proportional to the density of emergent vegetation. The total time spent at each pond varied from 2 to $121 \mathrm{~min}$, with more time spent at ponds with a greater pond perimeter and higher amounts and densities of emergent vegetation. We also conducted four visual surveys between 5 May and 26 June, 2007 using the same sampling protocol as in 2006.

\section{Measurement of local variables}

We quantified local pond variables to control for their effects in the statistical models. The local pond variables measured were: average $\mathrm{pH}$, average conductivity, pond area, percent cover of emergent and floating vegetation within $2 \mathrm{~m}$ of the pond edge, amount of overhanging vegetation, degree of insolation (sun exposure), and amount of forest cover within $100 \mathrm{~m}$ of the pond edge. All measurements were taken in the spring/summer of 2006. We measured $\mathrm{pH}$ and conductivity at four 
Fig. 2. Map of the study area. The area shown is located in eastern Ontario, approximately $100 \mathrm{~km}$ south of Ottawa and $100 \mathrm{~km}$ southwest of Montreal, with the St. Lawrence River forming the boundary between Canada and the USA.

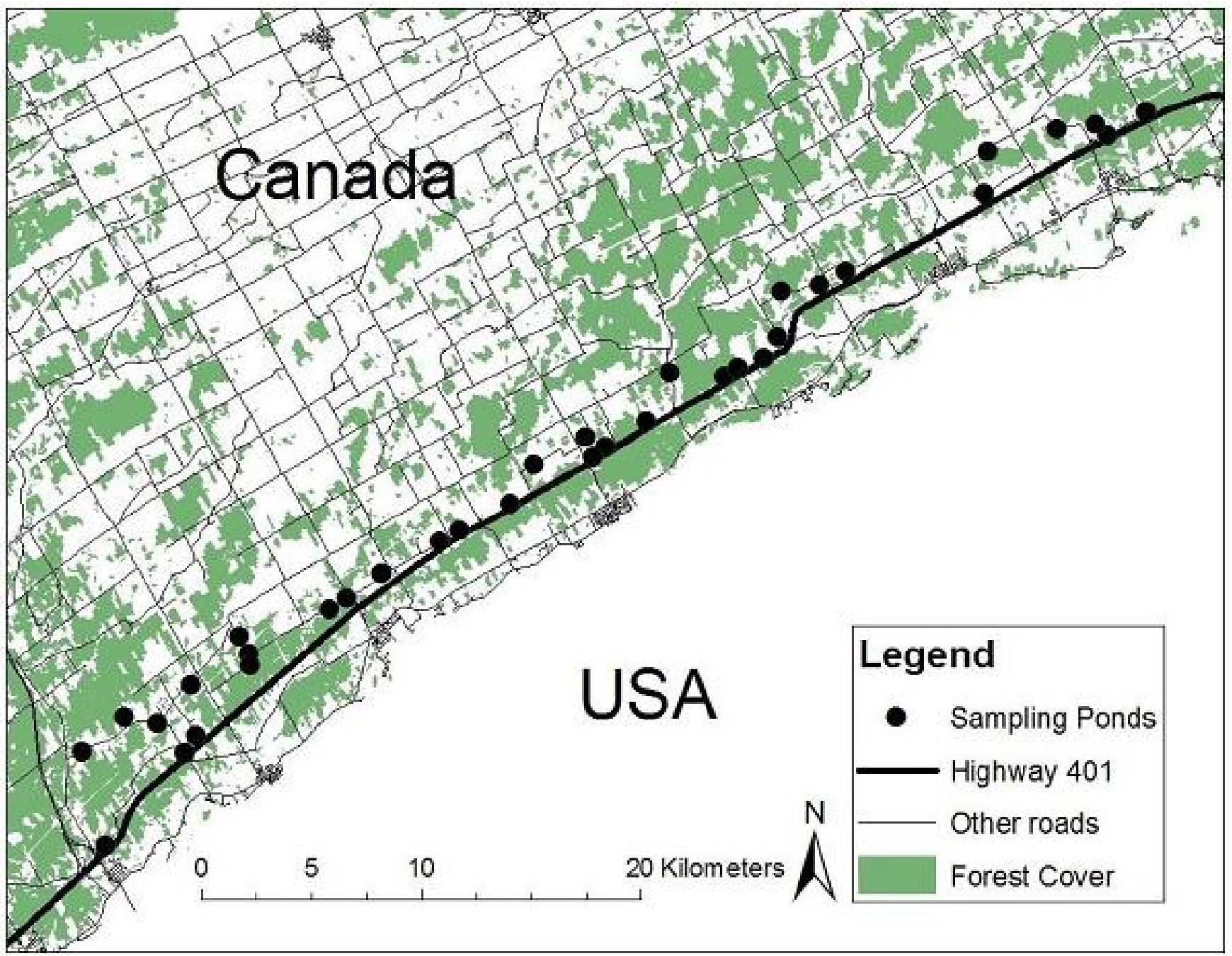

points at each pond; both $\mathrm{pH}$ and conductivity can have significant effects on anurans (e.g., Pope et al. 2000, Weyrauch and Grubb 2004, Babbitt et al. 2006). Species richness can be positively correlated with pond area (Laan and Verboom 1990). We measured pond area, using a handheld GPS unit with submetre resolution (Trimble GeoExplorer, Trimble Navigation Ltd., Westminster, Colorado, USA). Overhanging vegetation may provide calling sites for treefrogs, and also affects the amount of sunlight at a pond, which, together with the amount of emergent and floating vegetation near the pond edge, has been shown to affect the abundance of leopard and green frogs (Pope et al. 2000, Carr and Fahrig 2001).

We measured the amount of overhanging vegetation, degree of insolation and percent cover of emergent and surface vegetation with systematic surveys of each pond using line transects perpendicular to the pond edge at evenly spaced intervals $(19,38,56$, or $76 \mathrm{~m})$ so that at least 4 
transects were taken at each pond (Gagné and Fahrig 2007, Eigenbrod et al. 2008a). We took up to 20 transects for very large ponds with many types of habitat at the pond edge. At each transect we recorded whether there were trees overhanging the edge of the pond, degree of insolation within $2 \mathrm{~m}$ of the pond edge (full sun all day, shaded part of the day, shaded all day), percent cover of emergent vegetation, and the percent cover of surface vegetation at $1 \mathrm{~m}$ and $2 \mathrm{~m}$ from the pond's edge. We then averaged the values for each of these variables over all transects at each pond to come up with a single value for each variable for each pond. We obtained the amount of forest cover within $100 \mathrm{~m}$ of the edges of the ponds from digital 1:50 000 Natural Resources Canada topographic maps.

\section{Statistical analysis}

Chorus surveys have been found to be a good indicator of the relative abundance of many species of anurans (Shirose et al. 1997, Stevens and Paszkowski 2004). We used summed chorus counts as the response variable for all species except leopard frogs and green frogs. Summed chorus counts give weight to ponds with both consistent calling and high numbers of calling individuals (Pope et al. 2000). For green frogs and leopard frogs we used the maximum number of adults seen at a pond during the visual surveys as the response. Visual surveys have been shown to provide better estimates of green frog populations than chorus surveys (Nelson and Graves 2004), and chorus surveys can underestimate the presence of leopard frog populations (de Solla et al. 2005). It is also possible that we may not have heard the low, quiet calls of leopard frogs at ponds near Highway 401. We are confident that we were able to hear the calls of the other species over the noise of the highway. Only 7 of 9 species of anurans found in the study area were sufficiently common (minimum of 10 presences) for species-level analyses. Species richness was the total number of species of anurans seen or heard during all surveys at each pond.

To quantify the road-effect zones, we built a generalized linear regression and, when appropriate, a generalized, linear piecewise regression model for each species and for species richness. Because the distribution of the response varied among species, we used a Gaussian, Poisson, or negative binomial link function as appropriate. We used the $\mathrm{glm}$ function for the Gaussian and Poisson regressions, and the $g \operatorname{lm} . n b$ function in the MASS package (Venables and Ripley 2002) for the negative binomial models. We used the package segmented 0.1-4 (Muggeo 2004) for the piecewise regression. All analyses were performed in R 2.2 (R Development Core Team 2005). A piecewise linear regression with one breakpoint (Muggeo 2003, Toms and Lesperence 2003) is:

$Y=a+b_{1} X_{1}+\ldots+b_{\mathrm{j}} X_{. \mathrm{j}}+d D$ where $D<=$ breakpoint $T$

$Y=a+b_{1} X_{1}+\ldots+b_{\mathrm{j}} X_{. \mathrm{j}}+d D+(d+e)(D-T)$ where $D>T$,

where $Y$ is the response, $a$ is the intercept; $b_{1} \ldots b_{\text {i }}$ are the regression coefficients for all $X_{\mathrm{j}}$ local predictors; $d=$ the slope for distance to Highway $401(D)$ in the piecewise regression model to the left of the breakpoint $(T) ; e=$ "difference in slope parameter" so that $d+e$ is the slope of the line segment to the right of the breakpoint.

We only built piecewise regression models if an obvious breakpoint could be seen using a lowess smoothing function in the scatterplot between the response, i.e., after controlling for local variables, and distance to highway (Figs. 3 and 4), as recommended by Muggeo (2003) and Toms and Lesperence (2003). Piecewise regressions also require sensible initial estimates of the breakpoint (Muggeo 2003, Toms and Lesperence 2003) as the algorithm may otherwise converge to a local maximum rather than a global maximum if the initial estimate of the breakpoint is a long way from the true breakpoint. We ran piecewise regression models for each species and for species richness using ranges of estimates of the breakpoint in 100 $m$ intervals based on visual inspection of the lowess smoothing function and the scatterplot of the data.

To quantify the magnitude of the effect of Highway 401 on anurans, we compared the Akaike's Information Criterion including a correction for small sample size (AICc) values of the simple linear model, the piecewise regression model, and of an additional simple linear model, which was identical to the first, except that we log-transformed distance to Highway 401 (Table 1). We then calculated the percentage of deviance explained by distance to the highway for the best of these three models, i.e., the explained deviance of the term divided by the null deviance of the model (Crawley 1993) to estimate the explanatory power of this predictor (Table 2). We did not compare the log-transformed model to 
Fig. 3. Relationship between anuran relative abundance, species richness, and distance to Highway 401 (residuals after controlling for significant local predictors; Table 3) in $2006(n=34)$. The lowess smoothing line is shown. For species fitted with a piecewise regression model, the breakpoint of the best fitting model is shown by heavy solid vertical line; the second best-fitting breakpoint for the American toad, chorus frog, and species richness is shown by the second, but thinner, solid vertical line. One SD below the smallest breakpoint and 1 SD above the largest breakpoint are shown (dashed vertical lines). For the leopard frog and green frog, relative abundance was defined as the maximum number of adults seen during visual surveys. For all other species, relative abundance was defined as the chorus counts summed over all surveys.
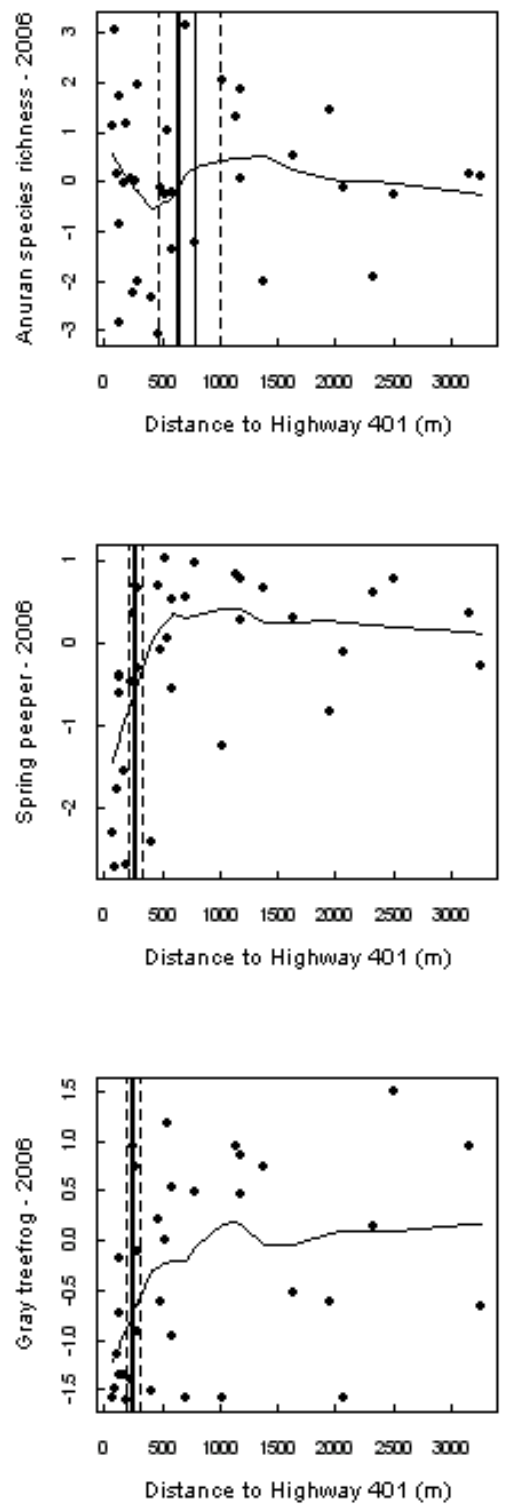
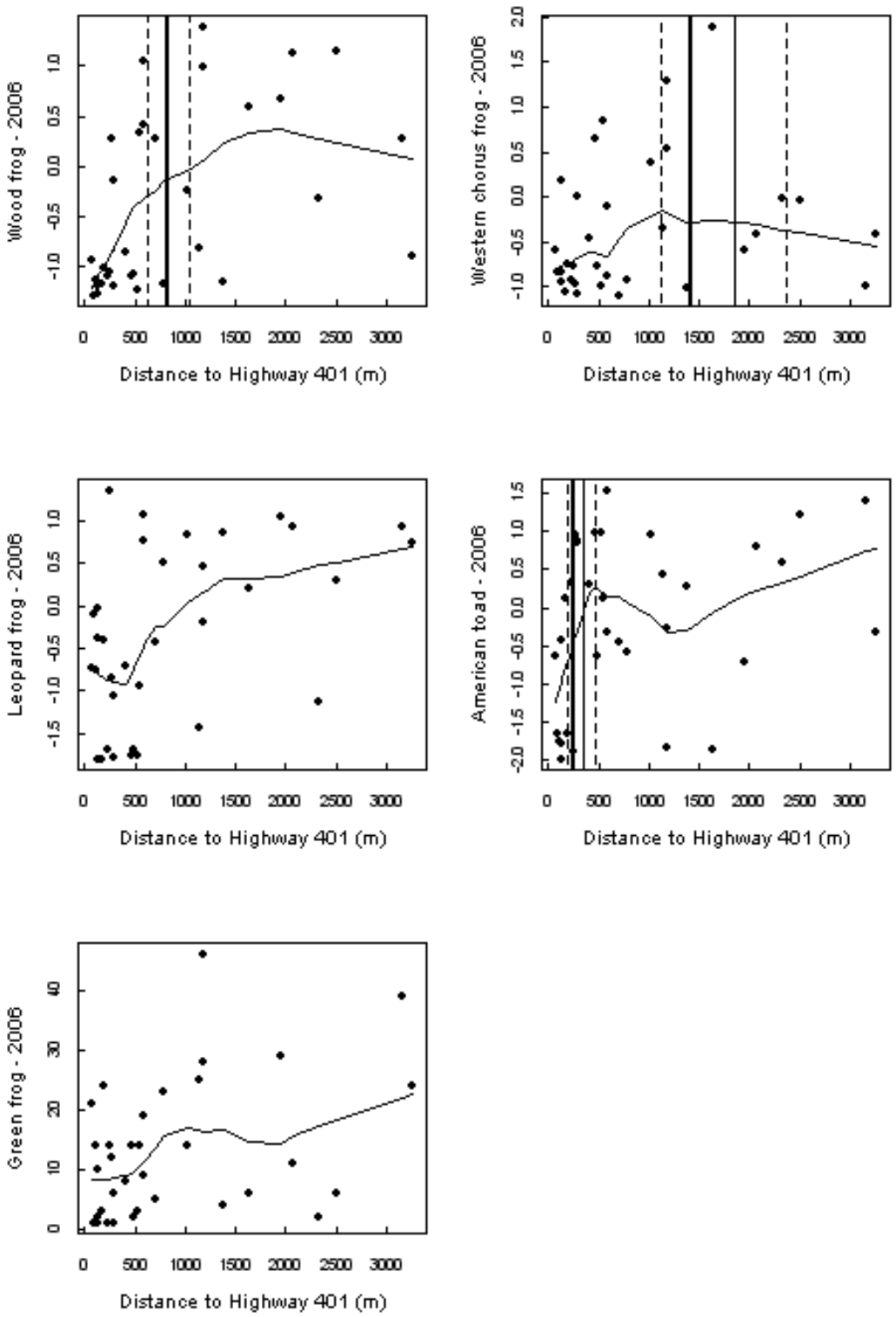
Fig. 4. Relationship between anuran relative abundance/species richness and distance to Highway 401 (residuals after controlling for significant local predictors; Table 3) in $2007(n=22)$. The lowess smoothing line is also shown. For species fitted with a piecewise regression model, the breakpoint of the best fitting model is shown by heavy solid vertical line; the second best-fitting breakpoint for the wood frog and the second and third best-fitting breakpoints for the gray treefrog are shown by thin solid vertical lines. One standard deviation below the smallest breakpoint and one SD above the largest breakpoint are shown (dashed vertical lines). For the leopard frog and green frog, relative abundance was defined as the maximum number of adults seen during visual surveys. For all other species, relative abundance was defined as the chorus counts summed over all surveys.
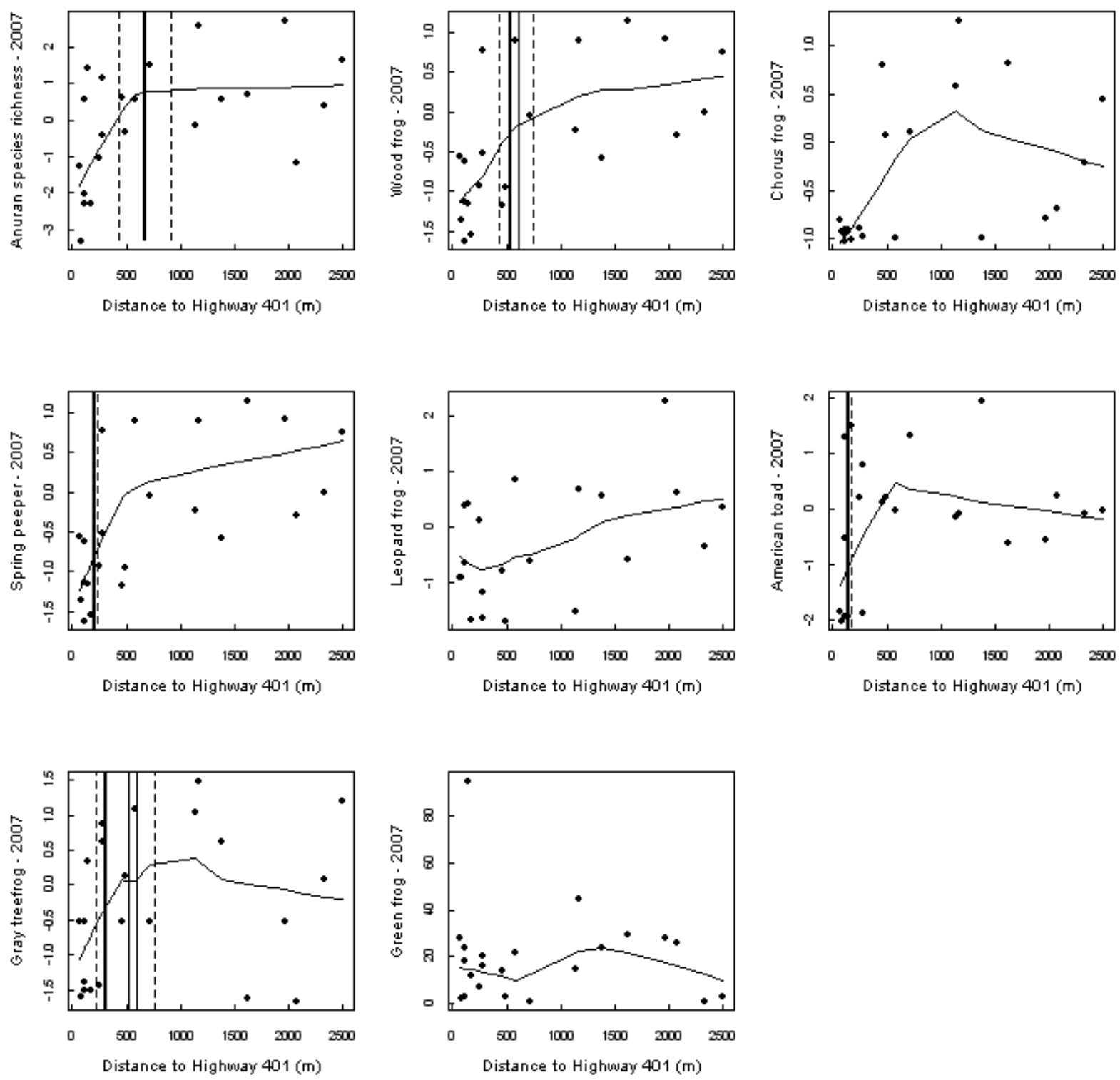
the linear or piecewise models when determining the extent and nature of the road-effect zone as logtransformation controls for a threshold-type response, but does not lend itself to identifying the distance from the road at which the threshold occurs.

The piecewise and linear regression models for each species except the western chorus frog and for species richness included any local pond variable that was present in the last step of a preliminary stepwise model selection procedure using AIC values (stepAIC; Venables and Ripley 2002; Table 3 ). We included all local pond variables and distance to Highway 401 in these preliminary stepwise models. However, automated selection using all local variables did not perform well for the western chorus frog because of the relatively low number of sites (11) at which this species was present. Instead, we compared the AICc, i.e., AIC adjusted for small sample sizes (Burnham and Anderson 1998) values of bivariate regressions in which each of the local variables was in turn the predictor for this species. The two best-fitting local variables, i.e., surface vegetation and proportion of overhanging trees, were indistinguishable from each other $(\triangle \mathrm{AICc}<$ 2)(Burnham and Anderson 1998), so we then included these two variables and distance to the 401 in a stepwise regression using stepAIC, which eliminated the proportion of overhanging trees from the final model (Table 3). Automated model selection procedures can lead to misidentification of correlated variables. However, we were only interested in eliminating the effects of pond-level factors in our analysis, and not in which local variables per se were the most important for a particular species. Thus, it mattered little in this study whether one highly correlated local variable or another was selected, as either variable would effectively be measuring the same pond-level variation.

We tested the significance $(\alpha=0.05)$ of the slope of the relationship between distance to Highway 401 and the response in the linear models. For the piecewise regression models, we tested the significance of the slope of the relationship between distance to the 401 before the breakpoint, and the significance of the "difference in slope parameter." We used a chi-square test of significance for the Poisson and negative binomial models, and an $F$ test for the Gaussian models. We compared overall model fit of the linear and piecewise regression models for each species and for species richness using the AICc value.
We built statistical models as described above using just the 2006 data. We then ran the same piecewise and simple linear regression models using the 2007 data to ensure that the breakpoints we found in 2006 were not simply a statistical artefact of the year in which sampling occurred (Table 4). We did not estimate the magnitude of the effect of the distance to the highway using the 2007 data as the smaller sampling effort in 2007 meant that the estimates of the magnitude of the effect of distance to Highway 401 were likely to be less reliable than those from 2006. Estimates of the breakpoints are also affected by sample size, but unlike explained deviance, their precision can easily be assessed by their standard error.

We checked for the presence of spatial autocorrelation of the residuals of the best-fitting model for each species (2006 data) by calculating Moran's I for all distance classes in spatial correlograms (Diniz-Filho et al. 2003). Spatial autocorrelation of the residuals of a statistical model invalidates the important assumption of most statistical tests that residuals are independent of each other. Positive spatial autocorrelation - which could, for example, be caused by nonindependence of the anuran populations at the sampling ponds can lead to underestimation of the confidence intervals, and thus inflation of Type I errors (Legendre 1993). We considered significant spatial autocorrelation to be present if at least one of the coefficients was significant at $\alpha / K$, where $K$ is the number of distance classes, and used Sturge's rule for determining the optimal number of distance classes (Legendre and Legendre 1998).

\section{RESULTS}

We found a statistically significant difference in slope parameter and that the piecewise regressions models gave at least as good a fit to the data as the linear models for anuran species richness as well as for five of seven species of anurans (wood frog, western chorus frog, spring peeper, American toad, and gray treefrog). The breakpoint occurred at approximately $450-800 \mathrm{~m}$ from the highway for species richness (two estimates of the location of the breakpoint), 200-300 $\mathrm{m}$ from the highway for the spring peeper, American toad (two estimates of the breakpoint), and gray treefrog; 600-1000 m from the highway for the wood frog, and 1100-2400 $\mathrm{m}$ from the highway for the chorus frog (two estimates of the breakpoint) (Table 1, Figs. 3 and 
Table 1. Summary of statistical models (2006 data) of the relationships between anuran relative abundance and anuran species richness and distance to Highway 401 as measured by linear, log-linear, and piecewise regressions. In cases in which more than one breakpoint was estimated $\left(^{*}\right)$, only the estimate from the bestfitting model is shown. Statistical significance of the coefficients is indicated as follows: $* \mathrm{P}<0.05 ; * * \mathrm{P}$ $<0.01 ; * * * \mathrm{P}<0.001$. N/A indicates that no piecewise regression was attempted as no threshold was apparent from visual examination of the data. We used a Gaussian link function for species richness and a Poisson link function for the American toad; all other analyses use the negative binomial link function.

\begin{tabular}{|c|c|c|c|c|c|c|c|c|}
\hline \multirow[t]{2}{*}{ Response } & \multicolumn{2}{|c|}{ Simple Linear Model } & \multicolumn{2}{|c|}{ Log Linear Model } & \multicolumn{4}{|c|}{ Piecewise Regression Model } \\
\hline & AICc & $\begin{array}{l}\text { Slope: } \\
\text { Distance to } \\
\text { Highway }\end{array}$ & $\mathrm{AICc}$ & $\begin{array}{l}\text { Slope: log } \\
\text { (Distance to } \\
\text { Highway) }\end{array}$ & $\mathrm{AICc}$ & $\begin{array}{l}\text { Breakpoint } \\
(\mathrm{m})\end{array}$ & $\begin{array}{l}\text { Slope before } \\
\text { breakpoint }\end{array}$ & $\begin{array}{l}\text { Difference } \\
\text { in Slope } \\
\text { Parameter }\end{array}$ \\
\hline $\begin{array}{l}\text { Species } \\
\text { Richness }\end{array}$ & 124.7 & $\begin{array}{c}0.0012 \\
\pm 0.0003 * * *\end{array}$ & 114.5 & $\begin{array}{c}1.160 \\
\pm 0.2017 * * *\end{array}$ & 119.8 & $\begin{array}{c}640.9 \\
\pm 183.1 *\end{array}$ & $\begin{array}{c}0.0049 \\
\pm 0.0015 * * *\end{array}$ & $\begin{array}{c}-0.0045 \\
\pm 0.0016 * *\end{array}$ \\
\hline $\begin{array}{l}\text { Wood Frog } \\
\text { Summed } \\
\text { Calling }\end{array}$ & 94.2 & $\begin{array}{c}0.0012 \\
\pm 0.0003 * * *\end{array}$ & 86.8 & $\begin{array}{c}1.291 \\
\pm 0.3152 * * *\end{array}$ & 94.1 & $\begin{array}{c}827.8 \\
\pm 204.7\end{array}$ & $\begin{array}{c}0.0038 \\
\pm 0.0016^{* * *}\end{array}$ & $\begin{array}{c}-0.0034 \\
\pm 0.0016 *\end{array}$ \\
\hline $\begin{array}{l}\text { Western } \\
\text { Chorus Frog } \\
\text { Summed } \\
\text { Calling }\end{array}$ & 78.7 & $\begin{array}{c}0.0009 \\
\pm 0.0004\end{array}$ & 76.2 & $\begin{array}{c}0.8939 \\
\pm 0.3886^{*}\end{array}$ & 74.2 & $\begin{array}{l}1470.0 \\
\pm 290.7\end{array}$ & $\begin{array}{c}0.0018 \\
\pm 0.0007\end{array}$ & $\begin{array}{c}-0.0063 \\
\pm 0.0019 *\end{array}$ \\
\hline $\begin{array}{l}\text { Spring Peeper } \\
\text { Summed } \\
\text { Calling }\end{array}$ & 200.7 & $\begin{array}{c}0.0003 \\
\pm 0.0002\end{array}$ & 193.5 & $\begin{array}{c}0.4310 \\
\pm 0.1126^{* * *}\end{array}$ & 189.6 & $\begin{array}{c}273.8 \\
\pm 55.77\end{array}$ & $\begin{array}{c}0.0094 \\
\pm 0.0047 *\end{array}$ & $\begin{array}{c}-0.0094 \\
\pm 0.0047 * * *\end{array}$ \\
\hline $\begin{array}{l}\text { Leopard Frog } \\
\text { Maximum } \\
\text { Adults }\end{array}$ & 154.6 & $\begin{array}{c}0.0007 \\
\pm 0.0002 * *\end{array}$ & 153.1 & $\begin{array}{c}0.6209 \\
\pm 0.1830 * * *\end{array}$ & 156.7 & $\begin{array}{c}935.9 \\
\pm 412.0^{*}\end{array}$ & $\begin{array}{c}0.0019 \\
\pm 0.0009 * *\end{array}$ & $\begin{array}{l}-0.0016 \\
\pm 0.0010\end{array}$ \\
\hline $\begin{array}{l}\text { American Toad } \\
\text { Summed } \\
\text { Calling }\end{array}$ & 112.6 & $\begin{array}{c}0.0002 \\
\pm 0.0001\end{array}$ & 110.8 & $\begin{array}{c}0.2631 \\
\pm 0.1294 *\end{array}$ & 109.0 & $\begin{array}{c}246.4 \\
\pm 56.35^{*}\end{array}$ & $\begin{array}{c}0.0107 \\
\pm 0.0041\end{array}$ & $\begin{array}{c}-0.0106 \\
\pm 0.0041 *\end{array}$ \\
\hline $\begin{array}{l}\text { Gray Treefrog } \\
\text { Summed } \\
\text { Calling }\end{array}$ & 129.2 & $\begin{array}{c}0.0004 \\
\pm 0.0002\end{array}$ & 125.8 & $\begin{array}{c}0.5268 \\
\pm 0.1988 * *\end{array}$ & 127.2 & $\begin{array}{l}245.9 \\
\pm 54.1\end{array}$ & $\begin{array}{c}0.0163 \\
\pm 0.0101\end{array}$ & $\begin{array}{c}-0.0162 \\
\pm 0.0101 * *\end{array}$ \\
\hline $\begin{array}{l}\text { Green Frog } \\
\text { Maximum } \\
\text { Adults }\end{array}$ & 246.0 & $\begin{array}{c}0.0003 \\
\pm 0.0001 *\end{array}$ & 245.8 & $\begin{array}{c}0.2827 \\
\pm 0.1368 *\end{array}$ & N/A & N/A & N/A & N/A \\
\hline
\end{tabular}

4). For species richness, the wood frog and the spring peeper, there was also a statistically significant relationship with distance to the highway up to the threshold distance (Table 1), with the linear model for the wood frog providing as good a fit to the data as the piecewise regression model (Burnham and Anderson 1998).
For one species - the leopard frog - there was no significant change in slope in the piecewise regression models and the linear regression model gave a better fit than the piecewise regression model, while for the green frog no piecewise regression was attempted as no threshold could be visually identified. The leopard frog and green frog did show 
Table 2. Percentage of deviance explained by distance to the motorway (2006 data). The best-fitting model was determined by comparing the AICc values of the simple linear regression, log-linear regression (distance to Highway 401 was log-transformed) and piecewise regression models (Table 3 ) for each species and for species richness.

\begin{tabular}{lll}
\hline \hline Species & Best fitting regression model & $\begin{array}{l}\text { Percent of deviance explained by distance to } \\
\text { motorway }\end{array}$ \\
\hline Species Richness & log-linear & 50.4 \\
Wood Frog & log-linear & 41.8 \\
Western Chorus Frog & piecewise & 34.3 \\
Spring Peeper & piecewise & 31.5 \\
Leopard Frog & log-linear & 23.5 \\
American Toad & piecewise & 25.5 \\
Gray Treefrog & log-linear & 14.2 \\
Green Frog & log-linear & 11.2 \\
\hline
\end{tabular}

a significant linear increase in abundance with increasing distance to the highway (Table 1, Fig. 3).

Distance to Highway 401 explained a large amount of the variation in anuran species richness $(51 \%$ of deviance explained). The proportion of the relative abundance of the individual species of anurans explained by distance to the highway varied between $42 \%$ for the wood frog, and $11 \%$ for the green frog. For most species, log transforming distance to Highway 401 resulted in the best fitting model (Table 2).

Results between 2006 and 2007 were generally very similar, with piecewise regression models providing a good fit to the data for the same species in both years. Indeed, the best estimates of the breakpoint in 2007 were within 100 m of the 2006 estimates for all piecewise regression models except for the wood frog, for which the best estimate of the breakpoint was $530 \mathrm{~m}$ from the highway in 2007 and $828 \mathrm{~m}$ from the highway in 2006 (Table 4, Figs. 3 and 4). A highly significant $(P<0.01)$ linear relationship between leopard frog abundance and distance to the highway was also present in both years. The only major change was for the green frog, for which there was no significant association with distance to the highway in $2007(P=0.60)$, as was present in 2006 (Table 1). No significant spatial autocorrelation was detected for any species.

\section{DISCUSSION}

Our results show that road-effect zones delineated by thresholds exist for species richness and for five of seven species of anurans, and that these extend from about 250 to $1000 \mathrm{~m}$ from the highway. The other two other species, i.e., leopard frog and green frog, showed a significant linear negative response to proximity to Highway 401, but no threshold-type relationship. For these latter two species, the roadeffect zone appeared to extend at least $1000 \mathrm{~m}$ from the highway (Fig. 3). All species of anurans in the study were thus negatively affected by the motorway, but these negative effects varied greatly in their nature (threshold vs. linear response), extent of thresholds where present, and magnitude.

Our findings indicate that comparing linear and piecewise regressions is a useful method to quantify the shape of the distance response of wildlife to roads. However, for three of the six statistically significant piecewise regression models, we found 
Table 3. Local pond variables included in both the linear and piecewise regression models. Only local variables that were present in the last step of a preliminary stepwise model selection procedure (stepAIC; Venables and Ripley 2002) that included all local pond variables as well as distance to Highway 401. We only included two local variables (surface vegetation and proportion of overhanging trees) and distance to the 401 in the stepwise model for the western chorus frog. See methods for explanation.

\begin{tabular}{ll}
\hline \hline Response & Local Variables \\
\hline Species Richness & Pond Area, \\
Surface Vegetation \\
Wood Frog Summed Calling & $\begin{array}{l}\text { Surface Vegetation, } \\
\text { Emergent Vegetation }\end{array}$ \\
Western Chorus Frog Summed Calling & Surface Vegetation \\
Spring Peeper Summed Calling & pH, \\
Leopard Frog Maximum Adults & Surface Vegetation \\
American Toad Summed Calling & Conductivity, Surface Vegetation \\
Gray Treefrog Summed Calling & pH \\
Green Frog Maximum Adults & Pond Area \\
\hline
\end{tabular}

more than one estimate of the location of the breakpoint. This is likely a result of there being a zone in which threshold effects exist, rather than a sharp break. Non clear-cut breakpoints may result in differences in breakpoint estimates and wide confidence intervals in the breakpoint (Muggeo 2003). Other types of piecewise regression models allow for a more gradual transition rather than a sharp break; however, these require the estimation of an extra parameter and are not recommended for relatively small sample sizes (Toms and Lesperence 2003).

A major, unexpected result of this study was the strength of the negative relationships between distance to the highway and relative abundance we found for five species that have previously been shown to be relatively unaffected by roads and traffic, i.e., the spring peeper, chorus frog, wood frog, and, to a lesser extent, the gray treefrog and green frog (Carr and Fahrig 2001, Trenham et al. 2003, Weyrauch and Grubb 2004, Mazerolle et al. 2005, but see Houlahan and Findlay 2003). Indeed, in an earlier study examining the relative effects of traffic and forest cover at the landscape scale in the same region, but not focused on Highway 401, we did not find significant effect of traffic for any of the above species (Eigenbrod et al. 2008a). The magnitude of the effect of road traffic in the latter study was also less that the magnitude of the effect of Highway 401 on for the leopard frog (7\% explained deviance vs. $23.5 \%$ ), American toad (12.3\% vs. $25.5 \%)$, and species richness (34\% of explained deviance vs. 50\%). These results also show that log-transformation of distance to the road is very useful if the goal of an investigation is to measure the magnitude of the effect of a road on wildlife and the data indicate a threshold-type response.

We hypothesize that the threshold-type relationships between anuran abundance and distance to Highway 401 we observed in this study and the unexpectedly strong negative effect of the highway on wood frog, spring peeper, chorus frog, and gray treefrog abundance are both a result of the reduced use of breeding habitat near Highway 401. There are two likely reasons for this: 
Table 4. Comparison of the threshold distance ( \pm 1 SD) from 2006 and 2007 that the road effect zone of Highway 401 extended into the landscape for anuran relative abundance and species richness, as estimated from the breakpoints of piecewise regressions. For cases in which more than one breakpoint was estimated (*) (e.g., American toad in 2006; Figs. 3 and 4), only the estimate from the best-fitting model is shown. N/ A indicates that no statistically significant $(\mathrm{P}<0.05)$ "difference in slope parameter" was present, or that no piecewise regression was attempted because a threshold was not apparent from visual examination of the data. A piecewise regression was not attempted for the chorus frog in 2007 because of the low number of presences (7) of this species in that year.

\begin{tabular}{lcc}
\hline \hline Response & Breakpoint $(\mathrm{m})(2006)$ & Breakpoint (m) (2007) \\
\hline Species Richness & $640.9 \pm 183.1^{*}$ & $675.4 \pm 245.2$ \\
Wood Frog Summed Calling & $827.8 \pm 204.7$ & $529.94 \pm 94.6^{*}$ \\
Western Chorus Frog Summed Calling & $1417.0 \pm 290.7^{*}$ & N/A \\
Spring Peeper Summed Calling & $273.8 \pm 55.8$ & $211.8 \pm 26.6$ \\
Leopard Frog Maximum Adults & N/A & N/A \\
American Toad Summed Calling & $246.4 \pm 56.4^{*}$ & $149.8 \pm 27.1$ \\
Gray Treefrog Summed Calling & $245.9 \pm 54.1$ & $316.2 \pm 98.0^{*}$ \\
Green Frog Maximum Adults & N/A & N/A \\
\hline
\end{tabular}

Hypothesis 1: Anurans are avoiding breeding sites near Highway 401, most likely a result of the unusually high nighttime noise levels on the highway interfering with calling activity. Heavy trucks make up $40 \%$ of the total traffic volume on Highway 401, and truck traffic volumes remain high at night (Mary Anne Griepsma, Ontario Ministry of Transportation, personal communication), resulting in a near-continuous rumble of traffic $24 \mathrm{~h} / \mathrm{d}$. Most anuran calling (Oseen and Wassersug 2002) and movements are at night (Todd and Winne 2006), so nighttime traffic volumes are likely to have a much greater negative effect on anuran populations than daytime traffic volumes. Avoidance of habitat up to some distance from a road can result in a thresholdtype response. There is some evidence that anuran calling may be negatively affected by anthropogenic noise. Sun and Narins (2005) found that Microhyla butleri, which gives a high-intensity call, similar to the gray treefrog and spring peeper, reduced calling intensity in the presence of low-frequency anthropogenic disturbances, i.e., traffic noise. Amphibians are also sensitive to seismic vibrations
(Duellman and Trueb 1986), but the influence of ground vibrations on amphibian activity has received limited study. There may also be fitness costs for anurans that breed in a noisy environment. Barrass (1985) showed reductions in egg masses of Bufo woodhousei and Hyla cinerea and disruptions in the mating systems of these species (reductions in noncalling males) in sites near a noisy highway compared to a control site, and there are preliminary indications that spring peepers increase both the intensity and frequency of their calling when subjected to recorded traffic noise (Glenn Cunnington, personal communication). A recent laboratory study also showed a reduced ability of female treefrogs (Hyla chrysoscelis) to orient towards male advertisement calls in the presence of traffic noise (Bee and Swanson 2007). Finally, L. ewingii, a small frog of the family Hylidae like the spring peeper, increased both its calling frequency and amplitude in response to traffic noise, with $37 \%$ more energy expended when calling in the noisiest vs. the quietest environment (Parris et al. 2009). This interference with acoustic communication could 
then lead to lower breeding success and smaller populations over time (Warren et al. 2006, Parris et al. 2009).

Hypothesis 2: Wood frog and spring peeper abundances near Highway 401 are low because of the inaccessibility of forest habitat on the other side of the 401. Although the total amount of forest within 500 and $1000 \mathrm{~m}$ of the edge of the survey ponds was uncorrelated with distance to Highway 401, there was a high correlation between the amount of forest within 500 and $1000 \mathrm{~m}$ of Highway 401 that could be reached without crossing Highway 401 (accessible forest) (Eigenbrod et al. 2008b) and distance to the highway $(r=0.84 ; P<0.0001$ and $r$ $=0.73 ; P<0.0001$, respectively for the two distances). The amount of forest in the landscape is known to be the best single predictor of both spring peeper and wood frog abundance (e.g., Homan et al. 2004, Porej et al. 2004, Gagné and Fahrig 2007), with both species dependent on forests for foraging and breeding habitat. Because the near-continuous flow of traffic on Highway 401 means that it is likely a near-complete barrier to the movement of anurans, the reduced forest cover available within 500-1000 $\mathrm{m}$ of ponds near the highway without crossing the highway likely has led to diminished populations of forest obligate species at these ponds. There is also a possibility that the barrier effect of the St. Lawrence River, which is located approximately 2 $\mathrm{km}$ south of Highway 401 (Fig. 2), may have reduced the accessibility of the wider landscape; thus, confounding the barrier effect of Highway 401. However, it seems unlikely that we would have seen the narrow (250-500 m), sharply defined roadeffect zones near the motorway if the true barrier was the river, which is over $2 \mathrm{~km}$ away from our study sites.

Both traffic noise and the reduced forest cover within 500-1000 $\mathrm{m}$ of the pond are likely correlated with distance to Highway 401, so we are unable to say which of the above two hypotheses was most likely to be causal. Traffic mortality may also have played a role in the low abundances of the American toad near the highway, because the related European toad (Bufo bufo) is known to be vulnerable to road mortality (Schlupp and Podloucky 1994, Hels and Buchwald 2001). The American toad was also negatively affected by traffic volumes in the landscape in an earlier study in the same region (Eigenbrod et al. 2008a) in which nighttime traffic noise was less of an issue.
The linear response of leopard frogs and green frogs to distance from the highway suggests that these two species were not avoiding breeding habitat near the highway, but rather that their low abundance near the highway was caused by road mortality. The leopard frog is known to be highly vulnerable to high-traffic roads (Carr and Fahrig 2001, Eigenbrod et al. 2008a), likely because of high road mortality (e.g., Ashley and Robinson 1996). The strength of the negative relationship with distance to the 401 for this species in this study is probably a result of the high traffic volumes (day and/or night) on the motorway. Although no previous study has shown a significant effect of road traffic on green frog populations (Carr and Fahrig 2001, Eigenbrod et al. $2008 a$ ), the latter study suggests that this species is reduced near roads with very high traffic volumes. The lack of a relationship between green frog abundance and distance to the highway in 2007 does suggest that this species is less adversely affected by traffic than the leopard frog, probably because of its lower vagility (Carr and Fahrig 2001). The low amounts of accessible forest cover in the landscape near the highway may also have contributed to the observed relationships for these species, though the amount of forest cover in the landscape is generally not an important predictor of either green frog or leopard frog presence or abundance (Guerry and Hunter 2002, Gagné and Fahrig 2007, Eigenbrod et al. 2008a, but see Houlahan and Findlay 2003). Both green and leopard frog abundances are clearly lower near Highway 401, but with their abundances still increasing $3000 \mathrm{~m}$ from the highway, the extent of the road-effect zone for these two species may exceed $3000 \mathrm{~m}$.

Predatory fish negatively affect many anurans (Hecnar and M'Closkey 1997, Smith et al. 1999), and because we were unable to control for them, $i$. e., they appeared to be present in most ponds, it is possible that this may have confounded our results. We compensated for the possible effect of fish by including all calling from within $100 \mathrm{~m}$ of the edge of our sample ponds in our chorus counts, as fishfree vernal pools and wetlands were nearly ubiquitous in the forests near our ponds. Vernal pools are important breeding habitat for the anurans in our study region that are also the most negatively affected by predatory fish, i.e., wood frogs, spring peepers, and gray treefrogs (Hecnar and M'Closkey 1997, Skelly et al. 1999). It is, however, possible that the relationship we observed between traffic density and leopard frog abundance is actually the 
result of the presence or absence of fish as this species rarely uses vernal pools for breeding. This seems unlikely, though, given that Carr and Fahrig (2001) also found a strong effect of road traffic on this species in a study conducted in ponds that were entirely in fish-free.

Anurans could also avoid pollution from the highway such as road salt (Sanzo and Hecnar 2006), but this is unlikely to have affected the results of our study. There was only a weak correlation $(r=-$ $0.19, P=0.28, n=34$ ) between conductivity and distance to the motorway, probably as none of the drainage ditches of Highway 401 emptied into any of our sampling ponds. We controlled for the effect of pollution by including conductivity as a local variable in the stepwise AIC procedure.

Our results indicate that the value of wetlands within $250 \mathrm{~m}$ of a major highway will likely be very low for anuran populations, given that all species were negatively affected within this distance in our study. We suggest that new roads should be at least $500 \mathrm{~m}$ from wetlands, as this distance corresponds to a conservative estimate of the road-effect zone for species richness. Ideally, this buffer distance should be much greater $(\sim 2 \mathrm{~km})$ given the standard errors associated with the road-effect zone for species richness, the $1000+\mathrm{m}$ road-effect zone we found for the chorus frog, and the findings of Carr and Fahrig (2001) and Eigenbrod et al. 2008a. Indeed, our results suggest that a buffer distance of at least $3000 \mathrm{~m}$, as suggested by Findlay and Houlahan (2003), may be necessary to ensure large populations of leopard frogs.

In addition to demonstrating the impacts of major intercity truck routes on anuran populations, our results add to the growing body of information on the effects of different types of roads on anurans. Previous studies have shown that high-traffic roads have a stronger negative effect on anurans than on low traffic roads (Fahrig et al. 1995, Hels and Buchwald 2001), and forestry roads with very low traffic volumes have no effect on anuran movements (deMaynadier and Hunter 2000). Our results suggest very high volumes of nighttime truck traffic can actually lead to reduced use of breeding habitat near these types of roads either by acting as a barrier to habitat on the other side of the road and/or resulting from traffic noise, leading to increased negative effects of these types of roads on species that are generally unaffected by traffic mortality, such as the spring peeper and wood frog. More research is needed to establish whether our findings for Highway 401 also hold near other major transportation routes, which seems likely, and if there is a threshold nighttime traffic volume that leads to avoidance of habitat near motorways. More work is also needed to test the hypothesis that anurans reduce their use of breeding habitat near major roads because of traffic noise.

Responses to this article can be read online at: http://www.ecologyandsociety.org/voll4/iss 1/art24/ responses/

\section{Acknowledgments:}

This study would not have been possible without the cooperation of many private landowners. We would also like to thank Kristen Keyes and Alison Callahan for their help in the field, many volunteers (especially Katy Heady, Wes von Papineau, Paul Sokoloff, and Anne and Dean Keyes) for their help with the fieldwork and with logistic support, and the members of the GLEL for their helpful comments on the manuscript. Also, many thanks to two anonymous reviewers and the subjecteditor, Rodney van der Ree, for their helpful comments that have greatly improved this manuscript. Funding was provided through a Natural Sciences and Engineering Research Council of Canada (NSERC) Doctoral Scholarship and Carleton University scholarships to FE, and NSERC Discovery Grants to SJH. and LF.

\section{LITERATURE CITED}

Ashley, E. P., and J. T. Robinson. 1996. Road mortality of amphibians, reptiles and other wildlife on the long point causeway, Lake Erie, Ontario. Canadian Field-Naturalist 110:403-412.

Babbitt, K. J., M. J. Baber, and L. A. Brandt. 2006. The effect of woodland proximity and wetland characteristics on larval anuran assemblages in an agricultural landscape. Canadian Journal of Zoology 84:510-519.

Barrass, A. N. 1985. The effects of highway traffic noise on the phonotactic and associated reproductive behaviour of selected anurans. 
Dissertation. Vanderbilt University, Nashville, Tennessee, USA.

Bee, M. A., and E. M. Swanson. 2007. Auditory masking of anuran advertisement calls by road traffic noise. Animal Behaviour 74:1765-1776.

Bishop, C. A., K. E. Petit, M. E. Gartshore, and D. A. MacLeod. 1997. Extensive monitoring of anuran populations using call counts and road transects in Ontario (1992 to 1993). Pages 149-160 in D. M. Green, editor. Amphibians in decline, Canadian studies of a global problem, herpetological conservation. Volume 1. Society for the Study of Amphibians and Reptiles, St. Louis, Missouri, USA.

Boarman, W. I., and M. Sazaki. 2006. A highway's road-effect zone for desert tortoises (Gopherus agassizii). Journal of Arid Environments 65:94-101.

Burnham, K.P., and D. R.Anderson. 1998. Model selection and inference: a practical informationtheoretic approach. Springer-Verlag, New York, New York, USA.

Carr, L. W., and L. Fahrig. 2001. Effect of road traffic on two amphibian species of differing vagility. Conservation Biology 15:1071-1078.

Coffin, A. W. 2007. From roadkill to road ecology: a review of the ecological effects of roads. Journal of Transportation Geograpy 15:396-406.

Crawley, M. J. 1993. GLIM for ecologists. Blackwell Scientific, London, UK.

Cushman, S. A. 2006. Effects of habitat loss and fragmentation on amphibians: a review and prospectus. Biological Conservation 128:231-240.

deMaynadier, P. G., and M. L. Hunter. 2000. Road effects on amphibian movements in a forested landscape. Natural Areas Journal 20:56-65.

de Solla, S. R., L. J. Shirose, K. J. Fernie, G. C. Barrett, C. S. Brousseau, and C. A. Bishop. 2005. Effect of sampling effort and species detectability on volunteer based anuran monitoring programs. Biological Conservation 121:585-594.

Diniz-Filho, J. A. F., L. M. Bini, and B. A. Hawkins. 2003. Spatial autocorrelation and red herrings in geographical ecology. Global Ecology and Biogeography 12:53-64.

Duellman, W. E., and L. Trueb. 1986. Biology of amphibians. John Hopkins University Press, Baltimore, Oregon, USA.

Eigenbrod, F., S. J. Hecnar, and L. Fahrig. $2008 a$. The relative effects of road traffic and forest cover on anuran populations. Biological Conservation 141:35-46.

Eigenbrod, F., S. J. Hecnar, and L. Fahrig. $2008 b$. Accessible habitat: an improved measure of the effects of habitat loss and roads on wildlife populations. Landscape Ecology 23:159-168.

Fahrig, L., J. H. Pedlar, S. E. Pope, P. D. Taylor, and J. F. Wegner. 1995. Effect of road traffic on amphibian density. Biological Conservation 73:177-182.

Forman, R. T. T., and L. E. Alexander. 1998. Roads and their major ecological effects. Annual Review of Ecology, Evolution, and Systematics 29:207-31.

Forman, R. T. T., and R. D. Deblinger. 2000. The ecological road-effect zone of a Massachusetts (USA) suburban highway. Conservation Biology 14:36-46.

Gagné, S. A., and L. Fahrig. 2007. Effect of landscape context on anuran communities in breeding ponds in the National Capital Region, Canada. Landscape Ecology 22:205-215.

Groffman, P., J. Baron, T. Blett, A. Gold, I. Goodman, L. Gunderson, B. Levinson, $M$. Palmer, H. Paerl, G. Peterson, N. Poff, D. Rejeski, J. Reynolds, M. Turner, K. Weathers, and J. Wiens. 2006. Ecological thresholds: the key to successful environmental management or an important concept with no practical application? Ecosystems 9:1-13.

Guerry,A.D., and M. L. Hunter. 2002. Amphibian distributions in a landscape of forests and agriculture: an examination of landscape composition and configuration. Conservation Biology 16:745-754.

Harding, J. H. 1997. Amphibians and reptiles of the Great Lakes region. University of Michigan Press, Ann Arbour, Michigan, USA. 
Hecnar, S. J., and R. T. M'Closkey. 1997. The effects of predatory fish on amphibian species richness and distribution. Biological Conservation 79:123-131.

Hels, T., and E. Buchwald. 2001. The effect of road kills on amphibian populations. Biological Conservation 99:331-340.

Homan, R. N., B. S. Windmiller, and J. M. Reed. 2004. Critical thresholds associated with habitat loss for two vernal pool-breeding amphibians. Ecological Applications 14:1547-1553.

Houlahan, J. E., and C. S. Findlay. 2003. The effects of adjacent land use on wetland amphibian species richness and community composition. Canadian Journal of Fisheries and Aquatic Sciences 60:1078-1094.

Huggett, A. J. 2005. The concept and utility of 'ecological thresholds' in biodiversity conservation. Biological Conservation 124:301-310.

Jaeger, J. A. G, J. Bowman, J. Brennan, L. Fahrig, D. Bert, J. Bouchard, N. Charbonneau, K. Frank, B. Gruber, and K. T. von Toschanowitz. 2005. Predicting when animal populations are at risk from roads: an interactive model of road avoidance behavior. Ecological Modelling 185:329-348.

Jaeger J. A. G, and L. Fahrig. 2004. Effects of road fencing on population persistence. Conservation Biology 18:1651-1657.

Keller, I., and C. R. Largiader. 2003. Recent habitat fragmentation caused by major roads leads to reduction of gene flow and loss of genetic variability in ground beetles. Proceedings of the Royal Society of London B: Biological Sciences 270:417-423.

Laan, R., and B. Verboom. 1990. Effects of pool size and isolation on amphibian communities. Biological Conservation 54:251-262.

Legendre, P. 1993. Spatial autocorrelation: trouble or new paradigm? Ecology 74:1659-1673.

Legendre, P., and L. Legendre. 1998. Numerical ecology. Second English Edition. Elsevier, Amsterdam, The Netherlands.
Luck, G. W. 2005. An introduction to ecological thresholds. Biological Conservation 124: 299-300.

Mace, R. D., J. S. Waller, T. L. Manley, K. Ake, and W. T. Wittinger. 1996. Relationships among grizzly bears, roads and habitat in the Swan Mountains, Montana. Journal of Applied Ecology 33:1395-1404.

Mazerolle, M. J., M. Huot, and M. Gravel. 2005. Behavior of amphibians on the road in response to car traffic. Herpetologica 61:380-388.

Muggeo, V. M. R. 2003. Estimating regression models with unknown break-points. Statistics in Medicine 22:3055-3071.

Muggeo, V. M. R. 2004. Segmented: segmented relationships in regression models. $\mathrm{R}$ package version 0.1-4. Available online at: http://www.R-pr oject.org.

Nelson, G. L., and B. M. Graves. 2004. Anuran population monitoring: comparison of the North American Amphibian Monitoring Program's calling index with mark-recapture estimates for Rana clamitans. Journal of Herpetology 38:355-359.

Oseen, K. L., and R. J. Wassersug. 2002. Environmental factors influencing calling in sympatric anurans. Oecologia 133:616-625.

Petranka, J. W., C. K. Smith, and A. F. Scott. 2004. Identifying the minimal demographic unit for monitoring pond-breeding amphibians. Ecological Applications 14:1065-1078.

Parris, K. M., M. Velik-Lord, and J. M. A. North. 2009. Frogs call at a higher pitch in traffic noise. Ecology and Society 14(1): 25. [online] URL: http: //www.ecologyandsociety.org/vol14/iss1/art25/

Pope, S. E., L. Fahrig, and N. G. Merriam. 2000. Landscape complementation and metapopulation effects on leopard frog populations. Ecology 81:2498-2508.

Porej, D., M. Micacchion, and T. E. Hetherington. 2004. Core terrestrial habitat for conservation of local populations of salamanders and wood frogs in agricultural landscapes. Biological Conservation 120:399-409.

R Development Core Team. 2005. $R$ : A language 
and environment for statistical computing. $\mathrm{R}$ Foundation for Statistical Computing, Vienna, Austria. Available online at: http://www.R-project. org.

Reijnen, R., R. Foppen, C. Ter Braak, and J. Thissen. 1995. The effects of car traffic on breeding bird populations in woodland. 3. Reduction of density in relation to the proximity of main roads. Journal of Applied Ecology 32:187-202.

Sanzo, D., and S. J. Hecnar. 2006. Effects of road de-icing salt $(\mathrm{NaCl})$ on larval wood frogs (Rana sylvatica). Environmental Pollution 140:247-256.

Schlupp, I., and R. Podloucky. 1994. Changes in breeding site fidelity: a combined study of conservation and behavior in the Common Toad Bufo bufo. Biological Conservation 69:285-291.

Semlitsch, R. A., J. R. Ryan, K. Hamed, M. Chatfield, B. Drehman, N. Pekarek, M. Spath, and A. Watland. 2007. Salamander abundance along road edges and within abandoned logging roads in Appalachian forests. Conservation Biology 21:159-167.

Shirose, L. J., C. A. Bishop, D. M. Green, C. J. MacDonald, R. J. Brooks, and N. J. Helferty. 1997. Validation tests of an amphibian call count survey technique in Ontario, Canada. Herpetologica 53:312-320.

Skelly, D. K., E. E. Werner, and S. A. Cortwright. 1999. Long-term distributional dynamics of a Michigan amphibian assemblage. Ecology 80:2326-2337.

Smith, G. R., J. E. Rettig, G. G. Mittelbach, J. L. Valiulis, and S. R. Schaackj. 1999. The effects of fish on assemblages of amphibians in ponds: a field experiment. Freshwater Biology 41:829-837.

Stevens, C. E., and C.A. Paszkowski. 2004. Using chorus-size ranks from call surveys to estimate reproductive activity of the wood frog (Rana sylvatica). Journal of Herpetology 38:404-410.

Sun, J. W. C., and P. M. Narins. 2005. Anthropogenic sounds differentially affect amphibian call rate. Biological Conservation 121:419-427.

Todd, B. D., and C. T. Winne. 2006. Ontogenetic and interspecific variation in timing of movement and responses to climatic factors during migrations by pond-breeding amphibians. Canadian Journal of Zoology 84:715-722.

Toms, J. D., and M. L. Lesperence. 2003. Piecewise regression: a tool for identifying ecological thresholds. Ecology 84:2034-2041.

Trenham, P. C., W. D. Koenig, M. J. Mossman, S. L. Stark, and L. A. Jagger. 2003. Regional dynamics of wetland-breeding frogs and toads: turnover and synchrony. Ecological Applications

13: $1522-1532$.

Trombulak, S. C., and C.A. Frissell. 2000. Review of ecological effects of roads on terrestrial and aquatic communities. Conservation Biology 14:18-30.

Venables, W. N., and B. D. Ripley. 2002. Modern applied statistics with S. Fourth Edition. Springer, New York, New York, USA.

Vos, C. C., and J. P. Chardon. 1998. Effects of habitat fragmentation and road density on the distribution pattern of the moor frog Rana arvalis. Journal of Applied Ecology 35:44 56.

Warren, P. S., M. Katti, M. Ermann, and A. Brazel. 2006. Urban bioacoustics: it's not just noise. Animal Behaviour 71:491-502.

Weyrauch S. L., and T. C. Grubb. 2004. Patch and landscape characteristics associated with the distribution of woodland amphibians in an agricultural fragmented landscape: an informationtheoretic approach. Biological Conservation 115:443-450. 